\title{
(อ) OPEN ACCESS \\ What constitutes a reasonable compensation for non- commercial oocyte donors: an analogy with living organ donation and medical research participation
}

\author{
Emy Kool $\odot,{ }^{1}$ Rieke van der Graaf, ${ }^{1}$ Annelies Bos, ${ }^{2}$ Bartholomeus Fauser, ${ }^{2}$ \\ Annelien Bredenoord ${ }^{1}$
}

${ }^{1}$ Medical Humanities, Julius Center for Health Sciences and Primary Care Utrecht, University Medical Center Utrecht, Utrecht, The Netherlands

${ }^{2}$ Reproductive Medicine and Gynecology, University Medical Centre Utrecht, Utrecht, The Netherlands

Correspondence to Ma Emy Kool; e.m.kool-3@umcutrecht.nl

Received 25 March 2019 Revised 2 July 2019 Accepted 16 July 2019 Published Online First 2 August 2019

\section{ABSTRACT}

There is a growing consensus that the offer of a reasonable compensation for oocyte donation for reproductive treatment is acceptable if it does not compromise voluntary and altruistically motivated donation. However, how to translate this 'reasonable compensation' in practice remains unclear as compensation rates offered to oocyte donors between different European Union countries vary significantly. Clinics involved in oocyte donation, as well as those in other medical contexts, might be encouraged in calculating a more consistent and transparent compensation for donors if the elements that constitute a reasonable compensation are explicated. In doing so, lessons can be learnt from living organ donation and medical research participation. Practices in which the elements of a reasonable compensation for the individuals involved have already been more defined in the literature. By means of analogical reasoning, we will outline the different components of a reasonable compensation and subsequently apply these to the context of oocyte donation. We will argue that oocyte donors should first of all be reasonably reimbursed direct expenses related to the donation, without standard remuneration of lost wages. Second, donating oocytes requests a serious time investment, therefore donors are entitled to suitable compensation for their time spent and efforts made. Finally, we will explain that a reasonable compensation consisting of these two components allows for altruism to remain the key value of oocyte donation for reproductive treatment. However, if we acknowledge that donors' motives are more complex and often include reasons from self-interest, the reasonable compensation may be complemented with modest (non)monetary benefits.

\section{INTRODUCTION}

The desirability of offering money to women who donate oocytes for reproductive treatment has been extensively discussed over the years. In one respect, it has been argued that allowing substantial offers of money to oocytes donors will commercialise reproduction; an aspect of human life that should remain intimate and private. ${ }^{1}$ Moreover, monetary offers raise ethical concerns as it could commodify bodily material, potentially exploit women, unduly influence donors' consent and stimulate donors to withhold medically relevant information which could negatively affect the health of the future child. ${ }^{2-4}$ At the same time, it is considered unfair to expect people to make substantial financial sacrifices when engaging in socially valuable activities..$^{5}$ Because people generally have a strong interest in giving birth and parenting, donating oocytes for reproductive treatment can be considered an activity which is socially valuable. ${ }^{6}$ In the course of the debate there is a growing consensus that offering oocyte donors a 'reasonable compensation' is ethically appropriate.' For example, it is argued that a reasonable compensation does not necessarily compromise voluntary decision-making if careful attention is given to donors' understanding of the risks and impact of donation. ${ }^{8}$ Furthermore, altruistic motivations are not necessarily compromised by a reasonable compensation, allowing for altruism to remain the central value of oocyte donation for reproductive treatment. $^{9}$ However, to avoid commodification of donor oocytes, compensation rates should not depend on the number and quality of the retrieved oocytes or the (phenotypical) characteristics of the donor. $^{10}$

That donors are allowed a 'reasonable compensation' is endorsed by the European Union (EU) Tissue and Cells directive. ${ }^{11}$ In Europe commercial oocyte donation is prohibited. EU member states should make sure that individuals do 'not gain money by making available (their) bodily tissue' but that they 'may receive compensation, which is strictly limited to making good the expenses and inconveniences related to the donation'. ${ }^{11}$ Nonetheless, what constitutes a 'reasonable compensation' in accordance with the directive is not clear at all. ${ }^{12}$ The confusion is illustrated by the fact that between as well as within European countries varieties in the level of compensation are offered, ranging from $€ 250$ to $€ 2000$ per donation cycle. ${ }^{13}$ Unfortunately, justifications for these rates are often not provided. Defining what constitutes a 'reasonable compensation' for oocyte donors within the EU legal framework could diminish this arbitrariness by encouraging practice to calculate compensation rates consistently and transparently. Moreover, a well-defined and transparent calculation of donors' compensation may resolve the remaining ethical concerns of financially compensating oocyte donors.

While oocyte donation is a relatively novel practice, the ethical question of what constitutes a reasonable compensation for individuals who share their bodily tissue for the well-being of others is not new. Instead of reinventing the wheel, there is reason to assume that lessons can be learnt from practices in which the components of a reasonable 
Box 1 Reasonable compensation for medical research subjects $^{161751}$

The act of participation in medical intervention studies:

Medical research refers to activities designed to develop or contribute to generalisable health knowledge and can be distinguished in observational and intervention studies. In case of intervention studies, participation generally entails:

- The endurance of a medical intervention for the purpose of science either with or without (potential) personal benefit, including treatments such as (small) surgical interventions, life-style interventions or the intake of (new) drugs. Sometimes participants may have to be hospitalised or visit the clinic at weekly intervals.

- Undergoing medical procedures to meet the objectives of the study, which may include additional hospital visits for blood draws, lumbar punctures, biopsies, cognitive tests, MRI scans or questionnaires.

The elements of the financial compensation:

Compensation varies depending on the duration of the intervention, the difficulty of reaching recruitment targets and whether it is a commercially or non-commercially driven study. In general compensation consists of:

- The reimbursement of direct expenses including costs for travelling, food and accommodation. Lost wages are generally not reimbursed. Rates should reflect true, or reasonably estimate, out of pocket expenses.

- Compensation for time spent and efforts made into study participation calculated in accordance with the 'wage payment model' in which time and efforts are compensated commensurate with standardised hourly wages for unskilled but socially essential jobs.

- Additional (non)monetary benefits if recruitment rates are difficult to reach, the study is evaluated as socially valuable and offers are not that strong as to induce unduly influences. The appropriateness of the offer of any additional benefit is evaluated in light of the risks and burdens involved in a particular study by a research ethics committee.

- Monetary benefits foremost include 'completion bonuses' stimulating individuals to finish study participation.

- Non-monetary benefits may include insight into research results, free healthcare services, medical insurance or educational materials.

compensation for the individuals involved are already more defined. For instance, how to reasonably reimburse living organ donors has been extensively discussed in recent years. ${ }^{121415}$ Likewise, what constitutes a reasonable compensation for medical research subjects is carefully defined in the research ethics literature. ${ }^{516} 17$ In all three practices, individuals are subjected to a medical intervention involving time, effort, and the endurance of uncomfortable and potentially risky procedures for the benefit of others without direct personal benefit (boxes 1-3). Therefore, analogies between oocyte donation and living organ donation and/or participation in medical research can and have been frequently drawn. ${ }^{18}$ While existing analogies have mainly been performed to evaluate the (un)desirability of offering money to oocyte donors as such, we draw a parallel in order to identify the components of which a reasonable compensation consists.

Analogical reasoning is a widely used methodology in ethical reflection within the medical context. ${ }^{19}$ Analogies help to find ways to reason about unfamiliar cases on the background of
Box 2 Reasonable compensation for living organ donors $^{141526}$

\section{The act of living organ donation}

Healthy individuals voluntarily donate one of their kidneys or part of their liver to patients who otherwise might not have received an organ from the deceased donor waiting list. For donors the intervention of donation generally entails:

- The endurance of a thorough medical examination to determine individuals fitness for donation, including a general physical examination, urine examination, ECG, scans of the kidneys or liver and multiple blood tests. The assessment usually takes 3 months.

- An assessment of donors' reasoning for donation and understanding of the risks and long-term impact by a mental health professional.

- Hospitalisation and surgically removal of the donated organ by means of modern laparoscopic technique. Recuperation from surgery takes between 6 to 8 weeks for kidney donors and 8 to 12 weeks for liver donors. Complication from surgery are rare.

- Follow-up screening after 1 to 5 months to examine donors' kidney or liver function and to evaluate their (physical and mental) recovery.

The elements of the financial compensation:

To safeguard donors' altruistic motives, only real expenses that relate to the donation are reasonably reimbursed. In some countries reimbursement programmes are funded by the state or private insurances. In general reimbursement consists of:

- The reimbursement of direct expenses directly related to the donation process, including costs for transportation, food and accommodation.

- The reimbursement of indirect expenses involving costs made or missed because of (physical) impairments resulting from the donation process, including care for relatives and missed income. The refund of donors' lost salaries is either done in full (sometimes with an upper limit) or commensurate with minimum wages in that particular country.

more familiar ones. Furthermore, they presume a principle of consistency, namely 'equal cases must be treated equally'. ${ }^{20}$ Trying to tackle an ethical issue solely from one moral principle or theory is often criticised for being remote from the realities of daily practice. Moreover, it may lead to multiple conclusions therefore failing to provide a sufficiently convincing answer. ${ }^{18}$ In analogical reasoning the ultimate resolution is not obtained from one particular theory, but by means of working back and forth between specific related cases, resulting in 'a converging impression of all the relevant facts and arguments'. ${ }^{21}$ Subsequently, it allows to evaluate the variety of underlying principles and theories in a particular case and determine which principles take precedence over others. ${ }^{18}$ In this paper we use analogical reasoning in both its explanatory and argumentative function. ${ }^{20}$ First, we will identify and explain the components of the reasonable compensation offered to living organ donors and medical research participants as described in the literature and guidelines. Second, we use analogical reasoning to argue which of the identified components of these reasonable compensation of the source cases are appropriate elements for the target case; oocyte donation. In our analysis we do not necessarily focus on aspects related to the purpose of oocyte donation (ie, research or 
Box 3 The act of oocyte donation for reproductive treatment $^{24424446}$

The process of donating ova for reproductive treatment involves both a medical intervention and (research) procedures including:

- The self-administering of daily hormone injections for a period of 2 to 3 weeks (depending on the hormone stimulation protocol) in order to mature multiple oocytes.

- The endurance of the ovum pickup, a minimally invasive procedure to obtain the matured oocytes either under local or total anaesthesia, depending on the woman's preference or the clinic's policy.

- The endurance of multiple medical procedures, including a physical examination, blood tests, genetic screening or family history anamneses, and two to three internal ultrasounds to evaluate the donors' ovarian reserve as well as the development of the maturing follicles.

- An assessment of donors' motivation for donation and understanding of the risks and long-term impact of donation by a mental health professional.

reproduction) because we believe these aspects are primarily relevant when arguing for or against the offer of financial incentives or a financial compensation as such. Instead, we focus on aspects of the actual input of donors (ie, the act of donating oocytes) to argue for what constitutes a fair transaction. Arguments from fairness are thus leading in our analysis. Furthermore, we do not analogise oocyte donation with phase I research in which the risks and benefits of the tested interventions are uncertain. There is sufficient proof that if mild stimulation protocols are used the procedure of donating oocytes is safe and effective. ${ }^{22-24}$ Finally, while using the word 'donation' is problematic in the context of commercial oocyte donation, we continue to use the term since our analysis is placed within the European legal framework that prohibits commercial oocyte donation. ${ }^{11}$

\section{Identifying the components of a reasonable compensation}

By taking a closer look at the practice of medical research with human subjects and living organ donation we identified three main components of a reasonable compensation, namely (1) the reimbursement of expenses, (2) the compensation for individuals' time spent and efforts made and (3) the offer of additional (non)monetary benefits. We summarised the description of the components of the reasonable compensation of both participation in medical research and living organ donation in boxes 1 and 2.

\section{Reimbursement of expenses}

A reasonable compensation for both medical research participants and living organ donors foremost consists of the reimbursement of expenses that are an (in)direct result from participations or donation. ${ }^{141517}$ This strategy is based on the view that individuals should not suffer financially from making a contribution to the social good. ${ }^{516}$ Because no (net) benefit is obtained, reimbursement of expenses generally provides little chance to unduly influence individuals. ${ }^{1625}$ In the context of living organ donation it is additionally argued that reimbursing expenses safeguards donors' altruistic motives and thus donation within a gift-relationship. ${ }^{1426}$ A difference can be made in the reimbursement of 'direct' and 'indirect' expenses. Direct expenses are actual out of pocket expenses related to the donation process such as costs for travelling and consumptions. Indirect expenses are costs made or missed because of (physical) impairments resulting from the donation process, including lost wages and costs for (informal) caregivers. ${ }^{14}$ Both living organ donors and research subjects are generally reimbursed costs for transportation, accommodation and food. ${ }^{1316}$ Because recuperation from organ donation takes relatively long (6 to 12 weeks), organ donors are likely to be impaired to care for themselves or their relatives and miss substantial hours (ie, weeks) from work. To minimise the financial sacrifices of organ donors and to prevent them from returning to work early against medical advice, lost wages and costs for home and/or child care are generally (partly) remunerated. ${ }^{1415}$ Research subjects are normally not reimbursed lost wages. The argument provided is that, standardised remuneration of lost income results in an uneven compensation between participants and may stimulate the recruitment of low-income subjects. ${ }^{27}$ Lost wages are only reimbursed if a research subject is harmed as a result of study participation and consequently is unable to work for a substantial period of time. ${ }^{16} 17$

\section{Compensation for time spent and efforts made}

Medical research subjects are additionally compensated for their invested time and efforts. The compensation is calculated in accordance with the so-called 'wage payment model' in which time and efforts are compensated commensurate with standardised hourly wages for unskilled but socially essential jobs. ${ }^{5} 161727$ Compensating participants' time and effort is considered acceptable because participants are increasingly viewed as equal contributors in knowledge acquiring for the improvement of medicine. ${ }^{28}$ Compensating participants' time and effort is based on three presumptions. First, participation in research requires little skill but does demand time, effort and the endurance of uncomfortable procedures that may involve (minor) risks. ${ }^{27}$ Second, we generally consider it fair to financially compensate individuals for the fair value of their time, efforts and contribution to socially valuable activities. ${ }^{16}$ In that respect, research participation is equated with (socially valuable) employment, in which it is widely accepted that peoples' efforts should be adequately compensated. ${ }^{1629}$ Third, individuals contributing to a study with equal efforts should be compensated in similar ways, guaranteeing equal 'pay' for equal 'work'. 5 The compensation for research subjects is often considered to compensate for an individual's willingness to accept the medical risks involved in study participation. ${ }^{30}$ However, the research ethics literature explicitly argues that compensation rates should not depend on the level of risk involved in the study since this may constitute an undue inducement, leading individuals to volunteer against their better judgement of the risks involved. ${ }^{161725}$

\section{Additional (non)monetary benefits}

The offer of additional (non)monetary benefits is controversial in both the context of medical research and living organ donation. In medical research offering additional though moderate benefits is only appropriate to recruit and retain enough participants for studies that are of great social importance. ${ }^{16}{ }^{17}$ The remaining shortage of donor organs induced the discussion on offering (non)monetary benefits to living organ donors or organise a regulated donor organ market to increase the number of organ donors. ${ }^{31-33}$ Still, many scholars object to these suggestions, emphasising the importance of organ donation within a gift-relationship and the possibility of undue influencing and exploiting donors. ${ }^{12}{ }^{34-37}$ Moreover, it is argued that first financial 'disincentives' (ie, financial barriers) for organ donation should be minimised before financial incentives are considered. For instance, by assuring a (state funded) comprehensive 
Box 4 Degree of controversy of different components of a reasonable compensation

\section{Accepted}

Reimbursement of direct out-of-pocket expenses

Reimbursement of indirect expenses, such as lost wages

Compensation for actual time spent and efforts made

Offer of (non)monetary benefits

Controversial

reimbursement programme and proper insurance in case medical complications harmful to the donor occur. ${ }^{12} 3637$

\section{Applying the components of a reasonable compensation to the context of oocyte donation for reproductive treatment}

Box 4 provides an overview of the degree of controversy of the different components of a financial compensation, with 'the reimbursement of direct expenses' considered acceptable, and 'the offer of monetary benefits' the most controversial. We will now apply the identified elements of a reasonable compensation in the context of living organ donation and medical research to the context of oocyte donation, starting from the least controversial component: the reimbursement of expenses. Should oocyte donors be reasonably reimbursed (in)direct expenses, including lost wages?

Reasonably reimbursing oocyte donors' direct expenses is in line with the first part of the EU Tissue and Cell directive stating that compensation should be 'strictly limited to making good the expenses related to the donation'. ${ }^{11}$ Like living organ donors and research subjects, oocyte donors undergo medical procedures solely for the benefit of others. During the donation process, donors may have to visit the clinic multiple times for which they may incur costs for transportation and accommodation. Additionally, as oocyte donors typically have children of their own they may make expenses for child care (box 3). ${ }^{38}$ To prevent donors from suffering financially, reimbursement of these direct expenses seems fair. Whether oocyte donors are entitled to compensation for lost wages is less clear as policies between countries differ. ${ }^{39}$ Some argue that if oocyte donors miss substantial hours from work because of the visits to the clinic and the recuperation from oocyte retrieval, lost wages should be reimbursed to assure that donors remain 'financially neutral'. 812 Others provide the same arguments as in the context of medical research. Namely, allowing different levels of compensation to individuals with different levels of income, while they put the same efforts into donation, is unjust. Moreover, it may stimulate clinics to particularly recruit oocyte donors from low income groups. ${ }^{40}$ The analogy with living organ donation and medical research shows that indirect expenses, including lost wages, are only reimbursed if an individual has to recuperate from physical harm resulting from the medical intervention, and consequently is not able to work for a substantial period of time. Empirical studies on oocyte donors' experiences describe that the administering of the hormone injections takes little effort, and that generally donors need one full day to recuperate from the follicle puncture. ${ }^{83841}$ Thus, in contrast with the average time needed to recuperate from living organ donation, the damage incurred in the process of oocyte donation and the subsequent time to recover is rather minimal (boxes 2 and 3). Therefore, the act of and recuperation from oocyte donation does not (have to) prevent women from combining donation with paid work. Hence, lost wages do not necessarily need to be refunded.
However, in the unlikely event that an oocyte donor is seriously harmed with donating oocytes and therefore unable to work for a longer period of time lost wages and expenses for care for relatives should be reimbursed.

\section{Are oocyte donors entitled to be compensated for time and efforts?}

The actual process of donating oocytes is time-consuming and might incur financial losses for some women (box 3). To minimise these financial losses and acknowledge their time investment, oocyte donors could be compensated for their actual time and efforts into donation in accordance with the wage-payment model. Nonetheless, compensating research participants for time and effort has been criticised of framing research participation as 'labour' and a reasonable alternative for 'regular jobs'. ${ }^{29} \mathrm{~A}$ similar critique may be offered in the context of oocyte donation. Namely, compensating oocyte donors' time and efforts allows women to earn money by donating oocytes. This conflicts with the principle of non-commerciality and may encourage women to donate multiple times against their better interests. At the same time, the procedure of oocyte donation is not a pleasant undertaking. Since the procedure is associated with a small risk of ovarian hyper stimulation and ovarian infection, women are generally allowed to donate up to five times. ${ }^{42-44}$ Hence, it is highly unlikely that allowing a compensation for donors' time and effort will stimulate women to prefer oocyte donation over any other 'regular' job. Moreover, donating oocytes will not be a 'lucrative job' as compensation rates based on the wage payment model are relatively low. ${ }^{5}$

A second critique of compensating donors' time and effort based on minimum wages, is that it might frame the oocyte donor as an 'employee' which is counter-intuitive to common perspectives of oocyte donors as 'altruistic givers'. ${ }^{45}$ In that respect, some scholars have argued that compensating oocyte donors for their time and effort is only acceptable if donation is for research purposes. ${ }^{124046}$ It is reasoned that since donating for research does not (directly) result in the birth of a child, there is less reason to persist on pure altruistic motives compared with oocyte donation for reproductive treatment. The Nuffield Council continued by arguing that, because women are prepared to undergo risky procedures solely for the benefit of scientific progress, justice demands that their contribution should be recognised through compensating. ${ }^{12}$ Nonetheless, empirical research identified that reasonably compensating oocyte donors' contribution to reproductive treatment does not crowd out their altruistic motivations. ${ }^{38}$ Moreover, allowing a compensation for oocyte donors' time and efforts removes financial barriers to oocyte donation and actually stimulates altruistic donations. ${ }^{9}{ }^{33}$ Thus, if we allow oocyte donors to be compensated for their time and efforts, altruism could remain the central value of oocyte donation for reproductive treatment. Moreover, the actual efforts into donating oocytes, that is the endurance of the hormone stimulation programme and follicle puncture, are exactly the same for women donating for the purpose of reproduction as for the purpose of research (box 3]). Since donating oocytes for reproductive treatment or research purposes are both socially valuable activities, it is fair to recognise the contribution of both groups of donors by compensating the fair value of their time and efforts.

Finally, it may be questioned to what extent compensating oocyte donors' time and efforts is compatible with the EU Tissue and Cells directive. The directive prescribes that donors 'may receive compensation, which is strictly limited to making good the expenses and inconveniences related to the donation' 
(emphasis added). ${ }^{11}$ However, the extent to which something is experienced as an inconvenience or burden is personal and quantifying such discomfort rather arbitrary. ${ }^{8}{ }^{38}$ By understanding 'inconveniences related to the donation' as 'time spent and efforts made into donation', the wage payment model allows to transparently and consistently calculate the sum of money that reasonably compensates oocyte donors' contribution.

\section{Do monetary benefits fit within a reasonable compensation for oocyte donors?}

Today, multiple countries are in shortage of donor oocytes. As a result, many clinics are unable to treat (all) patients in need and direct these patients to seek cross-border reproductive care, which is an ethically sensitive practice on its own. ${ }^{47}$ The offer of financial incentives to oocyte donors is often considered to resolve the shortage of donor oocytes. ${ }^{948}$ However, allowing donors to financially benefit from donation raises ethical concerns similar to those present in the discussion on the desirability of a financial compensation as such. First of all, offering benefits conflicts with the conviction that donation of bodily tissue, including oocytes, should be an altruistic gift. Nonetheless, multiple scholars have argued that persisting on donations being purely altruistic is a 'charade' - as a result of which the demand for donor oocytes (and organs) may never be met. ${ }^{49} 4950$ Besides, peoples' actions are generally motivated by a combination of reasons. ${ }^{50}$ Empirical studies with oocyte donors identified that donors' motivations are complex. Alongside altruism donors are motivated by reciprocity, solidarity as well as (financial) self-interest. ${ }^{13} 38$ If we acknowledge that donors (may) have mixed motives for donation, offers encouraging donation could be supported. These offers may include (modest) monetary or non-monetary benefits, such as free extended carrier screenings or gynaecological care. Apart from the (in)compatibility with altruism, offering additional benefits to donors raises concerns on the validity of donors' consent and recipients' fair access to treatment. First, if donors are persuaded by the benefits to overlook the impact of donation that is the birth of a child (able to seek contact in the future) both donor and child may be harmed. Second, to what extent a particular benefit constitutes an undue inducement differs between individuals. ${ }^{25}$ Concerns on undue inducements should be taken into account when determining what are appropriate benefits and emphasise the importance of a careful informed consent process. ${ }^{16}$ Additionally, the financial compensation for oocyte donors is often settled in recipients' treatment costs. Supplementing donors' compensation with monetary benefits increases the costs of treatment, diminishing access for people with limited financial means. ${ }^{48}$ Thus, there is significant reason to first minimise the barriers to donating oocytes before the offer of additional benefits is considered. Similar to living organ donation, efforts could be made to increase societal awareness on the need for (more) oocyte donors. ${ }^{1238}$

\section{Lessons learnt: the reasonable compensation for oocyte donors}

The premise underlying analogical reasoning is to 'treat equal cases equally'. ${ }^{19}$ At the same time, no two cases are identical, including the cases in our analysis. The obvious difference between the cases discussed here is that oocyte donation for reproductive treatment is aimed at the birth of a child. This makes the provision of monetary compensation to donors more controversial. Still, it is considered fair to 'reasonably compensate' oocyte donors and as a result of our analysis we now have a better understanding of how to do so. This insight
Box 5 Example of oocyte donors' compensation rate within the Dutch context

Reimbursement of direct expenses including *

- Transportation: mean $€ 158 /$ range: $€ 7-415$

- Child care: mean €135/range €15-513

Donors' average time and efforts into donation*

- Visits to the clinic (10 visits of 2 hour): 20 hours

- Administering hormone injections (18 days, twice a day 2 min): 1,2 hours

- Recuperation from follicle puncture: 8 hours

Total time spend: 29,2 hours

National minimum wage for unskilled but essential jobs: $10 € / \mathrm{h}$ $29,2 * 10=292 \approx € 300$ for donors' time and efforts into donation

*based on empirical evidence of 43 donors of a Dutch oocyte bank ${ }^{41}$

could be useful to calculate the appropriate compensation for other individuals that share their bod(il)y (tissue) for the wellbeing of others as well, such as surrogates. As for oocyte donors for reproductive treatment we have learnt that a reasonable compensation is not intended to compensate donors' willingness to undergo the risks involved in donating oocytes, as it would unduly influence women to accept these risks against their better judgements. Instead, the first component of the reasonable compensation for oocyte donors is the reimbursement of expenses directly related to the donation, including costs for travelling, accommodation and child care. Because recuperation from donating oocytes takes generally 1 day, reimbursement should not necessarily include lost wages. Lost wages should only be reimbursed in the unlikely event that an oocyte donor is seriously harmed and therefore unable to work for a longer period of time. Nevertheless, oocyte donation does demand a considerable investment of time from women, which brings us to the second component of the compensation. Namely, that oocyte donors are entitled to compensation for their time spent and efforts made into donation. Because donating oocytes is a socially valuable activity, recognising the contribution of these women is justifiable. By compensating donors' time and efforts in accordance with standardised hourly wages for unskilled but socially essential jobs (ie, the wage payment model) the compensation rate for donors' contribution into reproductive treatment can be calculated transparently and consistently. Box 5 shows an example of a compensation for oocyte donors within the Dutch context calculated in accordance with the identified elements (box 5). A financial compensation consisting of these two components allows for altruism to remain the key value of oocyte donation for reproductive treatment. Nonetheless, beliefs about oocyte donors being solely altruistically motivated do not necessarily correspond with reality. Acknowledging peoples' reasons for actions, including those of oocyte donors, are complex and could comprise self-interested motivations, opens up the possibility of offering (non)monetary benefits as a third component of the reasonable compensation provisioned that donors' informed consent is carefully assessed. In any case, what we consider appropriate benefits for oocyte donors needs to be discussed further. First barriers to oocyte donation should be removed. Increasing societal awareness on the need for donors and providing a reasonable compensation to oocyte donors that is transparent and consistently calculated is a first step in this direction. 
Acknowledgements We would like to thank the reviewers for their constructive comments on the manuscript.

Contributors EMK and RG designed the study and EMK drafted the first manuscript. RG, AMEB, BCJMF and ALB made substantial contribution to the paper and revised it critically. All authors have read and approved the final manuscript.

Funding Funding was provided by the Dutch grand supplier the Netherlands Organization for Health Research and Development (ZonMw), grant number: 70-73000-98-200.

Competing interests $A M E B$ and $B C J M F$ are the initiators of the UMC Utrecht oocyte bank. During the most recent 5 years period, BCJMF has received fees or grant support from the following organisations (in alphabetic order): Actavis/ Watson/Uteron, Controversies in Obstetrics \& Gynecology (COGI), Dutch Heart Foundation, Dutch Medical Research Counsel (ZonMW), Euroscreen/Ogeda, Ferring, London Womens Clinic (LWC), Merck Serono (GFI), Myovant, Netherland Genomic Initiative (NGI), OvaScience, Pantharei Bioscience, PregLem/Gedeon Richter/ Finox, Reproductive Biomedicine Online (RBMO), Roche, Teva and WHO

Patient consent for publication Not required.

Provenance and peer review Not commissioned; externally peer reviewed.

Open access This is an open access article distributed in accordance with the Creative Commons Attribution Non Commercial (CC BY-NC 4.0) license, which permits others to distribute, remix, adapt, build upon this work non-commercially, and license their derivative works on different terms, provided the original work is properly cited, appropriate credit is given, any changes made indicated, and the use is non-commercial. See: http://creativecommons.org/licenses/by-nc/4.0/.

ORCID iD

Emy Kool http://orcid.org/0000-0003-3891-2518

\section{REFERENCES}

1 Coercion RR. Commercialization, and commodification: the ethics of compensation for egg donors in stem cell research. Berkeley Technol Law J 2006;21:1055-66.

2 Ahuja KK, Simons EG, Edwards RG. Money, morals and medical risks: conflicting notions underlying the recruitment of egg donors. Hum Reprod 1999;14:279-84.

3 Steinbock B. Payment for egg donation and surrogacy. Mt Sinai J Med 2004;71:255-65.

4 Mertes H, Pennings G, Dondorp WJ, et al. Financial compensations for oocyte donors: Soon to be a debate of the past? Hum Reprod 2012;27.

5 Dickert N, Grady C. What's the price of a research subject? Approaches to payment for research participation. N Engl J Med 1999;341:198-203.

6 Robertson JA. Children of choice:freedom and the new reproductive technologies. Princeton University Press: Princeton:, 1994.

7 Kool EM, Bos AME, van der Graaf R, et al. Ethics of oocyte banking for third-party assisted reproduction: a systematic review. Hum Reprod Update 2018;24:615-35.

8 Waldby C, Kerridge I, Boulos M, et al. From altruism to monetisation: Australian women's ideas about money, ethics and research eggs. Soc Sci Med 2013:94:34-42.

9 Pennings G. Central role of altruism in the recruitment of gamete donors. Monash Bioeth Rev 2015;33:78-88.

10 Pennings G, Vayena E, Ahuja K. Balancing ethical criteria for the recruitment of gamete donors. In: Richards M, Pennings G, Appleby JB, eds. Reproductive donation: practice, policy and bioethics. Cambridge: Cambridge University Press, 2012:150-67.

11 The European Parliament and the Council of the European Union. Directive 2004/23/ EC of the European Parliament and of The Council of 31 March 2004 on setting standards of quality and safety for the donation, procurement, testing, processing, preservation, storage and distribution of human tissues and cells. Off J Eur Union 2004;102:48-58.

12 Nuffield Council on Bioethics. Human bodies: donation for medicine and reseach. London, 2011

13 Pennings G, de Mouzon J, Shenfield F, et al. Socio-demographic and fertility-related characteristics and motivations of oocyte donors in eleven European countries. Hum Reprod 2014;29:1076-89.

14 Sickand M, Cuerden MS, Klarenbach SW, et al. Reimbursing live organ donors for incurred non-medical expenses: a global perspective on policies and programs. American Journal of Transplantation 2009;9:2825-36.

15 Kerremans B, Thuong F, Breidenbach G, et al. Toolbox living kidney donation. Eur Com 2016.

16 Gelinas L, Largent EA, Cohen IG, et al. A framework for ethical payment to research participants. N Engl J Med Overseas Ed 2018;378:766-71.
17 Council for International Organizations of Medical Science. International ethical guidelines for Health-Related Research Involving Humans. Geneva, Switserland, 2016.

18 Mertes H, Pennings $\mathrm{G}$. The force of dissimilar analogies in bioethics. Theor Med Bioeth 2011:32:117-28

19 Jonsen A, Toulmin S. The abuse of casuistry -a history of moral reasoning. Berkeley, Los Angeles, London: University of California Press, 1988.

20 Hofmann B, Solbakk JH, Holm S. Teaching old dogs new tricks: the role of analogies in bioethical analysis and argumentation concerning new technologies. Theor Med Bioeth 2006:27:397-413.

21 Sunstein CR. On analogical reasoning. Harv Law Rev 1993;106:741-91.

22 Ethics Committee of the American Society for Reproductive Medicine. Interests, obligations, and rights of the donor in gamete donation. Fertil Steril 2009;91:22-7.

23 Pennings $G$, de Wert G, Shenfield F, et al. ESHRE Task Force on Ethics and Law 12: Oocyte donation for non-reproductive purposes. Hum Reprod 2007;22:1210-3.

24 Shrestha D, La X, Feng HL. Comparison of different stimulation protocols used in in vitro fertilization: a review. Ann Trans/ Med 2015;3:137.

25 Grady C. Money for research participation: does in jeopardize informed consent? Am $J$ Bioeth 2001;1:40-4.

26 Giubilini A. Why and how to compensate living organ donors: ethical implications of the New Australian scheme. Bioethics 2015;29:283-90.

27 Grady C. Science and society Payment of clinical research subjects. I Clin Invest 2005;115:1681-7.

28 Dauda B, Dierickx K. Benefit sharing: an exploration on the contextual discourse of a changing concept. BMC Med Ethics 2013;14:1-8.

29 Lynch HF. Human Research Subjects as Human Research Workers. J Heal Policy, Law, Ethics 2014;14:122-93.

30 Largent EA, Grady C, Miller FG, et al. Money, coercion, and undue inducement: a survey of attitudes about payments to research participants. IRB 2012;34:1-8.

31 Joralemon D. Shifting ethics: debating the incentive question in organ transplantation. J Med Ethics 2001;27:30-5.

32 Erin CA, Harris J. An ethical market in human organs. J Med Ethics 2003;29:137-8.

33 Raddliffe-Richards J, Daar AS, Guttmann RD, et al. The case for allowing kidney sales. The Lancet 1998:351:1950-2.

34 Board S. Ethical Incentives - not for payment for organ donation. N Eng/ J Med 2002:346-.

35 Greasley K. A legal market in organs: the problem of exploitation. J Med Ethics 2014;40:51-6.

36 Klarenbach S, Garg AX, Vlaicu S. Living organ donors face financial barriers: A national reimbursement policy is needed. Can Med Assoc J 2006;174:797-8.

37 Reichardt J-0. Donor Compensation: An Ethical Imperative!. Transplant Proc 2010:42:124-5.

38 Kool EM, van der Graaf R, Bos AME, et al. Stakeholders views on the ethical aspects of oocyte banking for third-party assisted reproduction: a qualitative interview study with donors, recipients and professionals. Hum Reprod 2019;34:842-50.

39 Regulating DDL. or not) reproductive medicine: an alternative to letting the market decide. Indian J Med Ethics 2011;8:175-9.

40 Dickenson DL. The Lady Vanishes: What's Missing from the Stem Cell Debate. J Bioeth Inq 2006;3:43-54.

41 Ame B, Bakker MRC, Broekmans FJM, et al. Eiceldonatie : wie doen het en wat kost het ze ? Ned Tijdschr Geneeskd 2014;158:1-5.

42 Maxwell KN, Cholst IN, Rosenwaks Z. The incidence of both serious and minor complications in young women undergoing oocyte donation. Fertil Steril 2008:90:2165-71.

43 Sauer MV, Kavic SM. Oocyte and embryo donation 2006: reviewing two decades of innovation and controversy. Reprod Biomed Online 2006;12:153-62.

44 Interests A. obligations, and rights of the donor in gamete donation. Fertil Steril 2009;91:22-7

45 Almeling R. Sex sells: the medical market for eggs and sperm. Berkeley, Los Angeles, London: University of California Press, 2011.

46 Pennings G, de Wert G, Shenfield F, et al. ESHRE Task Force on Ethics and Law 12 oocyte donation for non-reproductive purposes. Hum Reprod 2007;22:1210-3.

47 Inhorn MC, Gürtin ZB. Cross-border reproductive care: a future research agenda. Reprod Biomed Online 2011;23:665-76.

48 Daniels KR. To give or sell human gametes - the interplay between pragmatics, policy and ethics. J Med Ethics 2000;26:206-11.

49 Pennings G. Gamete donation in a system of need-adjusted reciprocity. Hum Reprod 2005;20:2990-3.

50 Moorlock G, Ives J, Draper H. Altruism in organ donation: an unnecessary requirement?: Table 1. J Med Ethics 2014;40:134-8.

51 Altman D. Introduction to study design. EQUATOR Centre UK: University of Oxford, 2014 